\title{
Gastroprotective Effect of Conocarpus Erectus Plus Omega-3 on Experimentally Induced Ulcer in Rats
}

\author{
Zahraa M Ayad $^{1 *}$, Ali I. Alameedi ${ }^{2}$, Hassan Adheem Abbas ${ }^{3}$, and Laith S.G. Al-Rubaie ${ }^{4}$ \\ ${ }^{I}$ Department of Nursing, Al-Mustaqbal University College, Al Hillah, Iraq \\ ${ }^{2}$ Department of Physiology and Pharmacology, College of Veterinary Medicine, AlQasim Green University, Iraq \\ ${ }^{3}$ Al-Furat Al-Awsat Technical University/Technical Institute of Babylon, Iraq \\ ${ }^{4}$ Veterinary Directorate, Department of Biology and Medical Supervision, Baghdad, Iraq \\ *Corresponding author's Email: zahraa.mohammed@mustaqbal-college.edu.iq; (DORCiD: 0000-0003-0611-3084
}

\begin{abstract}
There has been a dearth of research on the gastroprotective effect of Conocarpus erectus in the literature so the current study was designed to estimate the ability of Conocarpus erectus (C. erectus) leaves extract alone and in combination with omega-3 regarding gastroprotective effects. A total of 30 male rats were divided into five groups $(\mathrm{n}=6)$. All animals induced gastric ulcer by $80 \mathrm{mg} / \mathrm{kg}$ of naproxen orally twice a day for three consecutive days. At the same time, the animals treated orally with $175 \mathrm{mg} / \mathrm{kg}$ omega- $3,250 \mathrm{mg} / \mathrm{kg}$ C. erectus, $80 \mathrm{mg}$ omega- $3+150 \mathrm{mg}$ C. erectus, $10 \mathrm{mg} / \mathrm{kg}$ of lansoprazole, and $2 \mathrm{ml} / \mathrm{kg}$ of DMSO were named T1, T2, T3, T4, and TC, respectively. The obtained results of the present study indicated the presence of flavonoids, saponin, and tannin as active ingredients in C. erectus leaves extract. Consequently, $C$. erectus seemed to have the potential of chelating metals in a concentration-dependent manner. Gross and histopathology findings showed the highly protective capability of $C$. erectus and omega-3 against ulcerative lesion, compared to the time each was used alone. The outcomes of the current study indicated that using $C$. erectus alone or plus omega-3 can protect the gastric mucosa from the ulceration induced by naproxen, and the chelating properties of $C$. erectus.
\end{abstract}

Keywords: Conocarpus erictus, Naproxen, Omega-3, Rat, Ulcer

\section{INTRODUCTION}

Gastric ulcer (GU) is one of the most popular gastrointestinal diseases affecting individuals of all ages. The simplest definition is small sores that appear on the lining mucosa of the stomach mainly caused by Hylicobacter pylori and prolonged swallowing of non-steroidal anti-inflammatory drugs (NSAIDs). Approximately, $4.1-10 \%$ of people are exposed to peptic ulcer disease during their lifetime (Ko et al., 2016). The broad-spectrum indications of NSAIDs contribute to extensively increased incidence of GU as used for relieving pain, reducing fever (analgesic properties), and alleviating anti-platelet aggregation (Wongrakpanich et al., 2018).

Indeed, the ulcers are affected when NSAIDs strongly inhibited COX1 that is responsible for the biosynthesis of prostaglandin leading to the inhibition of major protective defense of the stomach (Xiao et al., 2017). Clearly, NSAIDs extended to suppress the COX2 enzyme (Kuna et al., 2019). Conocarpus erectus (C. erectus) widely spread tree belongs to the family Combretaceae and it abundantly exists in tropical regions all around the world. Furthermore, many studies have shown that all parts of the plant are beneficial due to antioxidant, anticancer, and antimicrobial properties (Alameedi and Nahi, 2019). Docosahexaenoic acid (DHA) is an omega-3 long-chain polyunsaturated fatty acid found in fish oil with anti-inflammatory, neuroprotective, and cardioprotective effects (Dagai et al., 2009). Overall, Bradbury (2011) reported that the use of DHA as pure oil could remarkably reduce inflammation and oxidative stress, so it plays an important role in the inhibition of the pathogenesis in gastric ulceration.

In this regard, the current study aimed to assess the gastro-protective effects of Conocarpus erectus (C. erectus) leaves extract alone and in combination with omega-3 on an induced ulcer in rats.

\section{MATERIALS AND METHODS}

\section{Ethical approval}

The study was carried out after approval of the Scientific Committee in the Department of Physiology, Biochemistry, and Pharmacology, College of Veterinary Medicine, Al-Qasim Green University in accordance with ethical standards of animal welfare. 


\section{Chemicals}

Omega-3, naproxen, and lansoprazole were purchased from Bioactive ${ }^{\circledR}$ pharmaceutical company, UK. Naproxen dissolved in distilled water and orally administered at once at $80 \mathrm{mg} / \mathrm{kg}$ twice a day for 3 consecutive days (Naproxen was given to animals at fasting state or randomly administrated through a day).

\section{Plant preparation}

\section{Conocarpus erectus}

Fresh leaves of $C$. erectus were collected from an agricultural field in the Al-Najaf province, Iraq, during September 2019. After washing and shadow drying the leaves, they were crushed carefully by a blinder.

\section{Animals}

A total of 30 male rats (200-250 g, 8 weeks old) were obtained from the animal lab of College of Veterinary Medicine Al-Qasim Green University, Iraq. Animals fasted for 15 hours before the study. Following the first dose of naproxen, food and water were provided ad libitum up to the end of the experiment. Al-Qasim Green University committee of animal care performed the animal experiment.

\section{Plant extraction}

Hydro-alcoholic extraction of leaves of C.erectus powder was carried out according to Harborne (1984) and Alameedi and Nahi (2019). As can be seen in Table 1, the phytochemical ingredients were identified using a chemical reagent according to Adegoke et al. (2010).

Table 1. Phytochemical screening of Conocarpus erectus profile (identified chemically)

\begin{tabular}{|c|c|c|c|c|}
\hline & Ingredients extract & Principle and reagent & Positivity result & Reference \\
\hline 1 & Flavonoids $(0.2 \mathrm{~g})$ & Add to $2 \%$ sodium hydroxide solution & Intense yellow color & Adegoke et al. (2010) \\
\hline 2 & Alkaloids (0.5 g) & $\begin{array}{l}\text { Dissolved in } 5 \mathrm{ml} \text { of } 1 \% \text { dilute hydrochloric } \\
\text { acid }\end{array}$ & Yellow-colored precipitate & Adegoke et al. (2010) \\
\hline 3 & Terpenoids $(0.1 \mathrm{~g})$ & $\begin{array}{l}0.5 \mathrm{ml} \text { of chloroform followed by } 1 \mathrm{ml} \text { of } \\
\text { sulphuric acid }\end{array}$ & Reddish-brown precipitate & Evans et al. (2002) \\
\hline 4 & Tannins $(0.2 \mathrm{~g})$ & $\begin{array}{l}\text { Dissolve in D.W, three drops of ferric } \\
\text { chloride }\end{array}$ & $\begin{array}{l}\text { Brownish blue or dark } \\
\text { color }\end{array}$ & Adegoke et al. (2010) \\
\hline 5 & Steroids $(0.5 \mathrm{~g})$ & $\begin{array}{l}2 \mathrm{ml} \text { of chloroform }+2 \mathrm{ml} \text { of concentrated } \\
\text { sulfuric acid }\end{array}$ & Red color & Adegoke et al. (2010) \\
\hline 6 & Saponnins $(0.2 \mathrm{~g})$ & $6 \mathrm{ml}$ of DW and shaken by fortex & Foam formation & Evans et al. (2002) \\
\hline
\end{tabular}

DW: Distilled water

\section{Metal chelating capacity of Conocarpus Erectus}

Chelation is the bonding of molecules to metal ions. Chelating agents are organic or inorganic compounds that can bind to toxic metal ions to form complex structures for easily excreting toxicity from the body intracellularly or extracellularly (Swaran and Pachauri, 2010). The chelation of ferrous ion by extract was estimated according to Dinis et al. (1994). Briefly, the mixture of $0.1 \mathrm{mM}$ FeSO4 with $0.25 \mathrm{mM}$ of ferrozine led to the formation of a Fe2p-ferrozine complex, then his produced complex was added into $1 \mathrm{~mL}$ of the extract. The reaction was initiated by the addition of 0.2 $\mathrm{ml}$ of $5 \mathrm{mM}$ ferrozine complex solution. The mixture was shaken and left to stand at $37^{\circ} \mathrm{C}$ for 10 minutes. EDTA was considered as a positive control.

Metal chelating activity $=\{(\mathbf{A}$ control $-\mathbf{A}$ sample $) / \mathbf{A}$ control $\times 100\}$

Where, $\mathbf{A}_{\text {control }}$ is the absorbance without plant extract and $\mathbf{A}_{\text {sample }}$ signifies the absorbance in the presence of a plant extract.

\section{Experimental design}

After inducing ulcer, the animals were divided into five groups ( $n=6$ rats per group). The experimental groups of T1, T2, T3, and T4 received 175mg/kg.bw omega-3, $300 \mathrm{mg} / \mathrm{kb} . \mathrm{bw}$ C. erectus, omega-3 + C. erectus (1:1), and 10 $\mathrm{mg} / \mathrm{kg}$.bw lansoprazole, respectively. The control group was named TC which received Dimethyl sulfoxide (DMSO).

\section{Histopathology}

The rats fasted for 22 hours. At the end of treatments, the animals were euthanized in a diethyl ether euthanasia chamber. The current protocol was accepted by the Ethics Committee of the College of Veterinary Medicine, Al-Qasim Green University. A longitudinal incision of stomach tissue was done and a $5 \mathrm{~g}$ sample was fixed in $10 \%$ neutral 
formalin, then send to the histology lab to make the slides according to standard procedures as described by Luna (1968).

\section{RESULTS}

\section{Phytochemical analysis}

The hydro-alcoholic extract of $C$. erectus showed the presence of flavonoids, tannins, and saponins and the absence of alkaloids, steroids, and terpenoids (Table 2)

Table 2. Specific phytochemical compounds of Conocarpus erectus

\begin{tabular}{lc}
\hline Phytochemical composition & Hydro-alcoholic leave extract of Conocarpus erectus \\
\hline Flavonoids & + \\
\hline Alkaloids & - \\
\hline Terpenoids & - \\
\hline Tannins & + \\
\hline Steroids & - \\
\hline Saponins & + \\
\hline
\end{tabular}

\section{Chelating capacity}

The results of the study indicated that $C$. erectus extract contained a significant amount of $\mathrm{Fe} 2+(11 \mathrm{mg} / \mathrm{ml})$. Moreover, the Fe2+ chelating potential C. erectus was concentration dependent manner ( Diagram 1).

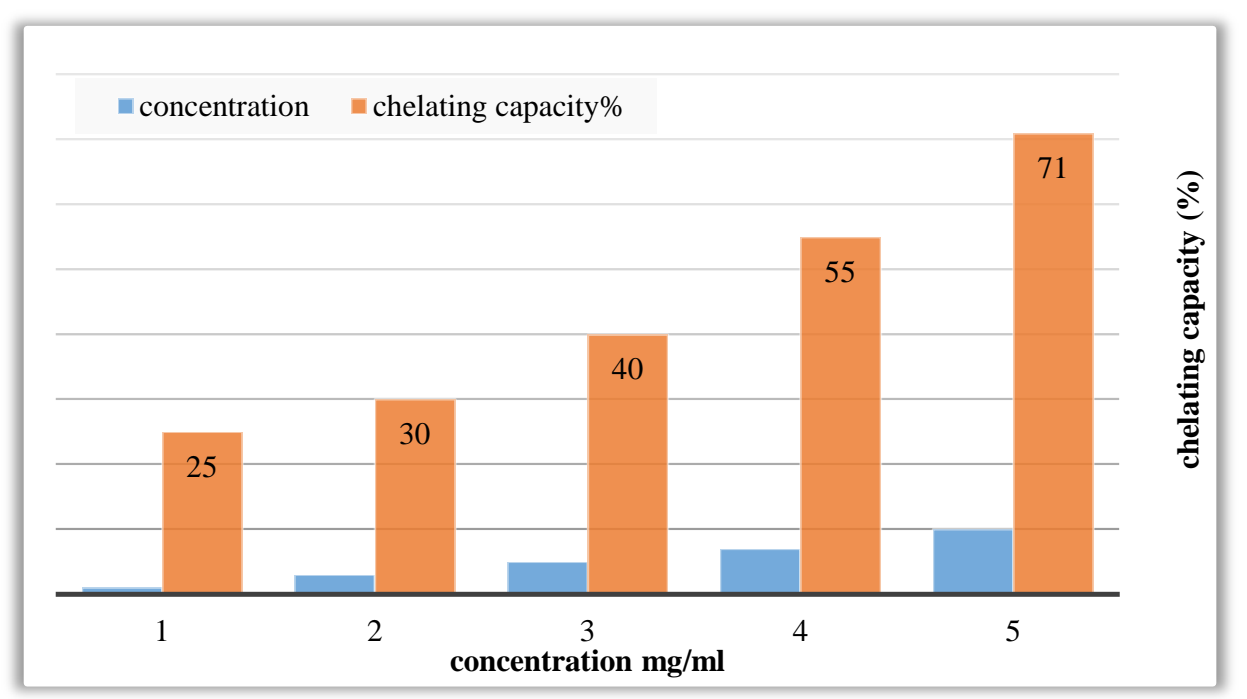

Diagram 1. Metal chelating capacity of Conocarpus erectus leaves

\section{Grossly inspection}

The gross lesion showed in Figure 1. There is an obvious gastric lesion in the mucosal layer represented by extensive mucosal hemorrhage and gastric hyperemia (Figure 1D), while the animals in the group pretreated with a combination of $C$. erectus + omega-3 indicated no ulcerative lesion leading to high protection against gastric ulcer (Figure 1B). The same protection against gastric lesions was observed in the group pretreated with lansoprazole (Figure 1E). Furthermore, moderate protection against gastric mucosal ulcer was determined in group T2 as pretreated with the C. erectus extract only (Figure 1C). Finally, the rat pretreated with omega-3 alone showed notable protection against gastric lesion induced by naproxen but less protection than compared groups T3 and T4 (Figure 1B, 2E).

\section{Histopathological results}

The presented gastric section showed complete loss of gastric mucosa leaving a few partial cells with an irregular appearance in the control group (DMSO, Figure 2A). Moreover, animals that received omega-3 at a dose of $175 \mathrm{mg} / \mathrm{kg}$ revealed the irregular appearance of gastric pits with various types of mononuclear cells (MNCS) noticed with subnuclear tissue with mild degenerations (Figure 2B, C, D). On the other hand, there was focal ulceration of gastric mucosa associated with necrotic debris in the lumen with squamous epithelial covering non-glandular stomach portion in animals received $300 \mathrm{mg} / \mathrm{kg}$ C. erectus as protective (Figure $2 \mathrm{C}$ ). Normal columnar mucosal epithelium covers the surrounding muscle with the prominence of parietal cells that appeared as fried eggs (C. erectus + omega-3). 


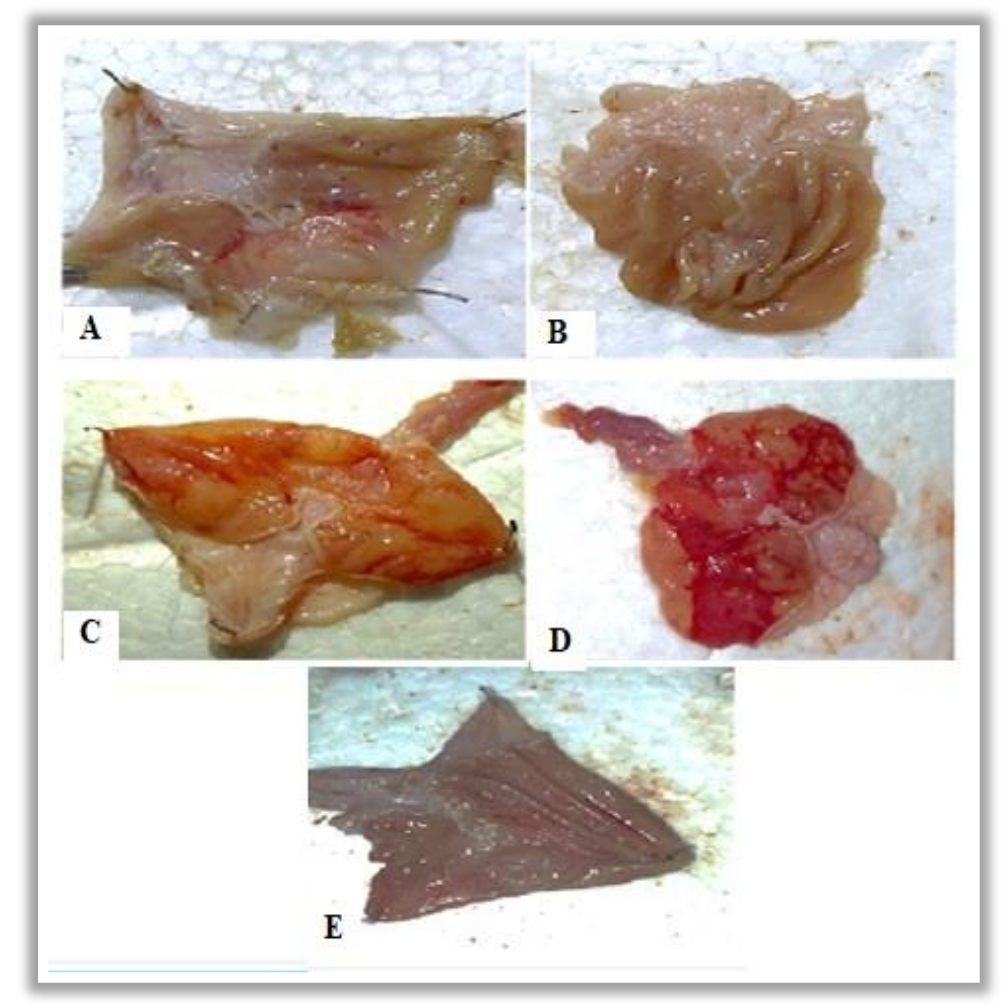

Figure 1. Gastric ulcer area induced by naproxen in rat. A: $175 \mathrm{mg} / \mathrm{kg}$. bw omega-3, B: combination C.erectus $(150 \mathrm{mg})+$ omega3 (85 mg ), C: C.erectus $300 \mathrm{mg} / \mathrm{kg} . b w$, D: Control Dimethyl sulfoxide, E: $10 \mathrm{mg} / \mathrm{kg} . b w$ Lansoprazole

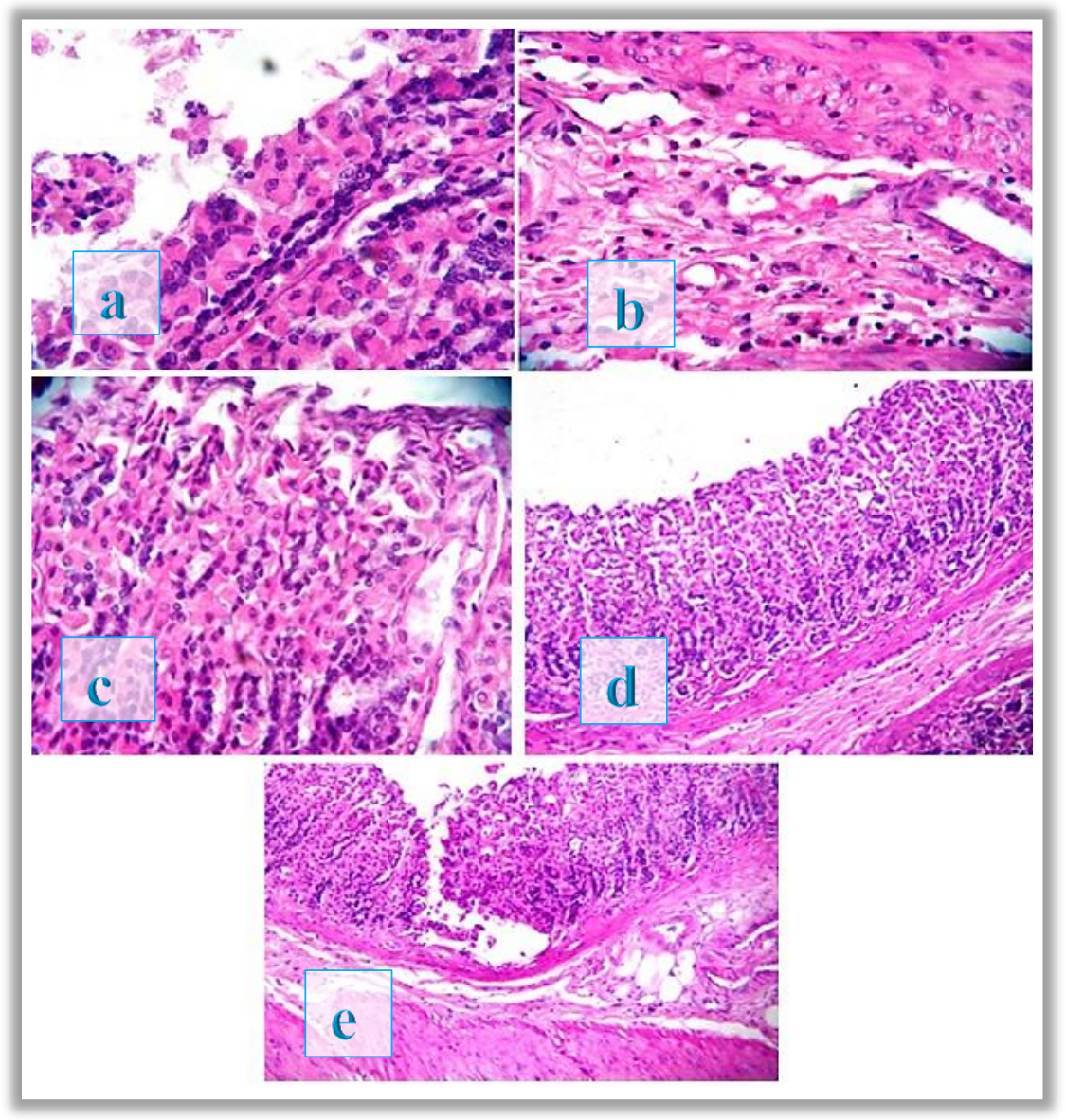

Figure 2. Histopathological changes of gastric tissue in rats with experimentally induced ulcer. a: Complete loss of gastric mucosa leaving a few partial cells with irregular finding (control group), b: Various types of mononuclear cells (MNCS) indicated subnuclear tissue (omega-3), c: Normal columnar mucosal epithelium covers the surrounding muscle with the prominence of parietal cells appeared as fried eggs (C. erectus +omega-3), d: Normal clear alteration of gastric mucosa and sub-mucosa with mild cellular infiltration (lansoprazole). e: Focal ulceration lesion observed with gastric mucus including a deeper sub-mucosal layer with the partial presence of parietal cells and peptic cells (C. erectus). 
The presence of many phytochemicals was detected in a hydro-alcoholic extract of $C$. erectus leaves as flavonoids, tannin, and saponin. The recorded components differed according to the location, weather, season, and water source (Nascimento et al., 2016). Studies on C. erectus leaves showed antimicrobial, antioxidant, anticancer, hepato-protective, and astringent properties of this plant (Shohayeb et al., 2013). All these pharmacological properties are directly related to phytochemical compositions, such as flavonoids, which have antioxidant, anti-inflammatory, and hepatoprotective effects (Lopes et al., 2000). Furthermore, saponin provides excellent anti-inflammatory action (Müller et al., 2006). The metal chelating capacity of C.erectus leaves extract revealed good chelating capabilities and concentration-dependent manner. The chelating potential of C.erectus created the impression that this activity was linked to the presence of flavonoids in the herbal plant, and consequently its antioxidant effect and scavenging of radicals, which was previously confirmed by (Wong et al., 2014). One of the main risk factors to inducing gastric ulcer are NSAIDs since they are known to cause erosion, antral ulceration, hemorrhage, and petechial bleeding on the gastric mucosa due to antiinflammatory, antipyretic and pain-relieving properties (Mohod and Bodhankar, 2013). The mechanism of naproxen in induced ulcers can be summarized by non-selectivity inhibition of COX1 and COX2 leading to a decrease in prostaglandin synthesis and mucous secretion.

Fallone et al. (2016) affirmed that when they used a combination of drugs for gastric ulcer therapy like (Amoxicilline, clarithromycine), the healing and recovery results were more promising, compared to the time each was used alone. Many studies discussed and confirmed that flavonoids revealed gastric cytoprotective activities by regulating prostaglandins biosynthesis pathways (Zhang et al., 2020). Furthermore, current results were consistent with those reported by Sharifi-Rad et al. (2018) and Khan et al. (2018) indicating that tannins and saponin showed a gastroprotective effect in animal studies.

The number of trials addressing the combined drug-flavonoid-containing plant in peptic ulcer therapy is fairly limited. Moreover, a combination of medicines and flavonoids exhibited better efficacy in the treatment of peptic ulcers, establishing a unique peptic ulcer therapy method. Alpha-linolenic acid, eicosapentaenoic acid (EPA), docosapentaenoic acid, and docosahexaenoic acid are omega-3 fatty acids. The EPA and DHA are important precursors for lipid-derived modulators that are known to contribute to anti-inflammatory effects.

Omega-3 is the major substrate for eicosanoid synthesis (Ahmed et al., 2020). Ozgocmen et al. (2000) and Wall et al. (2010) briefly suggested protective mechanisms of omega-3 as blocking the metabolism pathway of arachidonic acids, suppressing the inflammatory eicosanoids, adhesion molecules, and cytokines production; and increasing the levels of catalase enzyme within the peroxisome and in the cytoplasm resulting in enhanced defense against reactive oxygen species. Omega-3 increases the production of glutathione in gastric mucosa when glutathione act as a co-factor in some steps of prostaglandin E2 (PGE2) synthesis, so it will be assessed to convert PGG2 to PGH2 followed by conversion to PGE2, prostaglandins (PGs), leading to the protection of gastric mucosa against different types of gastric lesions (Sakr, 2016). The findings of the current study were supported by Ahmed et al. (2020) and Sakr (2016) when reported the role of omega-3 in the reduction of hyperacidity in rats. Moreover, the results of gross lesions were further confirmed with histopathological findings although the improving and protecting effects of C.erectus and omega-3 should gain more attention. While the animals received omega-3 at a dose of $175 \mathrm{mg} / \mathrm{kg}$, the irregular gastric pits appeared with various types of mononuclear cells (MNCS) with mild degenerations. On the other hand, focal ulceration of gastric mucosa was associated with necrotic debris in lumen observed in animals that received $300 \mathrm{mg} / \mathrm{kg}$ of C.erectus. Finally, normal columnar mucosal epithelium covers appeared as fried eggs in animals receiving combination therapy (C.erectus $150 \mathrm{mg} / \mathrm{kg}+$ omega-3 $80 \mathrm{mg} / \mathrm{kg}$ ), which was strongly similar to that of the lansoprazole group. Throughout the current observation of the phytochemical detection of the $C$. erectus, the protective role of $C$. erectus leaves and the omega-3 combination can be well observed, which was more efficient compared to the time each was used alone. In addition, the obtained results showed the positivity effect of flavonoids, tannin, and saponins and their significant role in scavenging the ROS produced by naproxen. Many studies focused on the role of omega-3 and flavonoids as antioxidants (Sakr, 2016; Zhang et al., 2020). It became clear the role of $C$. erectus and omega-3 in scavenging ROS can be resulted from naproxen; $C$. erectus and omega-3 were also confirmed to increase the production of PGE2 as protective to gastric mucosa. It can also play an important role in reducing the aggressive effects of the acidity of the stomach and increasing the mucous property.

\section{CONCLUSION}

According to the outcomes of the study, it can be concluded that C.erectus extract could have gastroprotective activity when used either alone or in combination with omega-3 that arising synergistic role in protection against ulcers. The use of natural medication as herbal and or omega-3 can provide efficient therapeutic effects against gastric ulcers. 


\section{DECLARATIONS}

\section{Authors' contribution}

All authors contributed equally to this work.

\section{Competing interests}

The authors declare that they have no conflict of interest.

\section{Ethical consideration}

Ethical issues (including plagiarism, consent to publish, misconduct, double publication and/or submission, and redundancy) have been checked by the authors.

\section{Acknowledgments}

The authors gratefully acknowledged the effort of all who reviewed and provided a helpful comment on the manuscript. All authors gratefully acknowledge the Department of Pharmacology and Physiology College of Veterinary Medicine, Al-Qasim Green University for their cooperation and assistance.

\section{REFERENCES}

Al-Ameedi AI, and Nahi H (2019). Therapeutic effects of hydro-alcoholic extract of clove buds and econocapus erictus on infected wounds healing in dogs. Advances in Animal Veterinary Sciences, 7(5): 389-396. DOI: https://www.doi.org/10.17582/journal.aavs/2019/7.5.389.396

Adegoke AA, IberI PA, Akinpelu DA, Aiyegoro OA, and Mboto CI (2010). Studies on phytochemical screening and antimicrobial potentials of Phyllanthus amarus against multiple antibiotic resistant bacteria. Antibiotic resistant bacteria. International Journal of Applied Research in Natural Products, 3(3): 6-12. Available at: https://www.scinapse.io/papers/1654034661

Ahmed OAA, Fahmy UA, Bakhaidar R, El-Moselhy MA, Okbazghi SZ, Ahmed AF, Hammad ASA, and Alhakamy NA (2020). Omega-3 self-nanoemulsion role in gastroprotection against indomethacin-induced gastric injury in rats. Pharmaceutics, 12(2): 140. DOI: https://www.doi.org/10.3390/pharmaceutics12020140

Bradbury J (2011). Docosahexaenoic acid (DHA): An ancient nutrient for the modern human brain. Nutrients, 3(5): 529-554. DOI: https://www.doi.org/10.3390/nu3050529

Dagai L, Peri-Naor R, and Birk RZ (2009). Docosahexaenoic acid significantly stimulates immediate early response genes and neurite outgrowth. Neurochemical Research, 34: 867-875. DOI: https://www.doi.org/10.1007/s11064-008-9845-z

Dinis TCP, Madeira VMC, and Almeida MLM (1994). Action of phenolic derivates (acetoaminophen, salycilate and 5aminosalycilate) as inhibitors of membrane lipid peroxidation and as peroxyl radical scavengers. Archives of Biochemistry and Biophysics, 315: 161-169. DOI: https://www.doi.org/10.1006/abbi.1994.1485

Evans WC, Evans D, and Trease GE (2002). Trease and Evans' pharmacognosy. Edinburgh: fifteenth edition. WB Saunders, pp. 214393. Available at: https://www.worldcat.org/title/trease-and-evan.

Fallone CA, Chiba N, van Zanten SV, Fischbach L, Gisbert JP, Hunt RH, Jones NL, Render C, Leontiadis GI, and Moayyedi P (2016). The Toronto consensus for the treatment of helicobacter pylori infection in adults. Gastroenterology, 151: 51-69. DOI: https://www.doi.org/10.1053/j.gastro.2016.04.006.

Harborne JB (1984). Photochemical methods a guide to modern technique of plant analysis. Champman and Hill, London, UK. Available at: https://moam.info/phytochemical-methods 59c14cec1723dde010230a1a.html.

Kuna L, Jakab J, Smolic R, Raguz-Lucic N, Vcev A, and Smolic M (2019). Peptic ulcer disease: A brief review of conventional therapy and herbal treatment options. Journal of Clinical Medicine, 8: 179. DOI: https://www.doi.org/10.3390/jcm8020179

Khan MSA, Khundmiri SUK, Khundmiri SR, Al-Sanea MM, and Mok PL (2018). Fruit-derived polysaccharides and terpenoids: Recent update on the gastroprotective effects and mechanisms. Frontiers in Pharmacology, 9: 1-9. DOI: https://www.doi.org/10.3389/fphar.2018.00569

Ko SH, Baeg MK, Ko SY, and Han K (2016). Do women who sleep more have reduced risk of peptic ulcer disease; korean national health and nutrition examination survey (2008-2009). Scientic Reports, 6: 1-6. DOI: https://www.doi.org/10.1038/srep36925.

Luna LG (1968). Manual of histologic staining methods of the Armed Forces Institute of Pathology. New York, Blakiston Division, McGraw-Hill. Available at: http://www.worldcat.org/oclc/330784.

Lopes RM, Oliveira TT, Nagem TJ, and Pinto AS (2000). Flavonóides: Farmacologia de flavonoides no controle hiperlipidêmico em animais experimentais. Revista Biotecnologia Ciência e Desenvolvimento, 3: 18-22. http://files.paulasennafarma.webnode.com.br/200000094-1f27420215/17_f.pdf.

Müller A, Ganzera M, and Stuppner H (2006). Analysis of phenolic glycosides and saponins in Primula elatior and Primula veris (Primula root) by liquid chromatography, evaporative light scattering detection and mass spectrometry. Journal of Chromatography A, 1112: 218-223. DOI: https://www.doi.org/10.1016/j.chroma.2005.10.067

Mohod SM, and Bodhankar SL (2013). Antiulcer activity of aqueous extract of leaves of Madhuca indica J. F. Gmel against naproxen induced gastric mucosal injury in rats. Journal of Acute Disease, 2(2): 127-133. DOI: https://www.doi.org/10.1016/S22216189(13)60112-2

Nascimento DKD, de Souza IA, de Oliveira AFM, Barbosa MO, Santana MAN, Júnior DFP, Lira EC, and Vieira JRC (2016). Phytochemical screening and acute toxicity of aqueous extract of leaves of conocarpus erectus Linnaeus in Swiss albino mice. Annals of the Brazilian Academy of Sciences, 88(3): 1431-1437. DOI: https://www.doi.org/10.1590/0001-3765201620150391

Ozgocmen S, Atalay Catal S, Ardicoglu O, and Kamanli A (2000). Effect of omega-3 fatty acids in the management of fibromyalgia syndrome, International journal of Clinical Pharmacology and Therapeutics, 38: 362-363. DOI: 
https://www.doi.org/10.5414/cpp38362

Shohayeb M, Abdel-hameed E, and Bazaid S (2013). Antimicrobial activity of tannins and extracts of different parts of Conocarpus erectus. International Journal of Pharmacy and BiologicalSciences, 3: 544-553. Available at: https://ijpbs.com/ijpbsadmin/upload/iipbs_51dbb691221f1.pdf

Sharifi-Rad M, Fokou P, Sharopov F, Martorell M, Ademiluyi A, Rajkovic J, Salehi B, Martins N, Iriti M, and Sharifi-Rad J (2018). Antiulcer agents: From plant extracts to phytochemicals in healing promotion. Molecules, 23: 1751. DOI: https://www.doi.org/10.3390/molecules23071751

Sakr HI (2016). The effect of omega-3 therapy on induced hyperacidity. Journal of Medical Science and Clinical Research, 4(2): 9222-9234. DOI: http://www.dx.doi.org/10.18535/jmscr/v4i0.25

Swaran JSF, and Pachauri V (2010). Chelation in metal intoxication. International Journal of Environmental. Research and Public Health, 7(7): 2745-2788. DOI: https://www.doi.org/10.3390/ijerph7072745

Wall R, Ross RP, Fitzgerald GF, and Stanton C (2010). Fatty acids from fish: The anti-inflammatory potential of long-chain omega-3 fatty acids. Nutrition Reviews, 68: 280-289. DOI: https://www.doi.org/10.1111/j.1753-4887.2010.00287.x

Wong FC, Yong AL, Ting EP, Khoo SC, Ong HC, and Chai TT (2014). Antioxidant, metal chelating, anti-glucosidase activities and phytochemical analysis of selected tropical medicinal plants. Iranian Journal of Pharmeutical Research, 13(4): 1409-1415. https://pubmed.ncbi.nlm.nih.gov/25587331/

Wongrakpanich S, Wongrakpanich A, Melhado K, and Rangaswami JA (2018). Comprehensive review of non-steroidal antiinflammatory drug use in the elderly. Aging Diseases, 9: 143-150. DOI: https://www.doi.org/10.14336/AD.2017.0306

Xiao X, Nakatsu G, Jin Y, Wong S, Yu J, and Lau JYW (2017). Gut microbiota mediates protection against enteropathy induced by indomethacin. Scientic Reports, 7: 40317. DOI: https://www.doi.org/10.1038/srep40317

Zhang W, Lian Y, Li Q, Sun L, Chen R, Lai X, Lai Z, Yuan E, and Sun S (2020). Preventative and therapeutic potential of Flavonoids in peptic ulcers. Molecules, 25(20): 4626. DOI: https://www.doi.org/10.3390/molecules25204626 